\title{
Commentary
}

\section{Designing a Renaissance for Digital News Media}

\author{
Anette Novak \\ Swedish Media Council, 11553 Stockholm, Sweden; E-Mail: anette.novak@statensmedierad.se
}

Submitted: 5 October 2018 | Accepted: 8 October 2018 | Published: 8 November 2018

\begin{abstract}
User participation in the journalistic context has theoretically been possible since the emergence of the Internet. The few interface formats which have been developed to link newsrooms and citizens have, however, not followed the same explosive development as other parts of the media landscape. One reason often referred to by the scientific community is the defensive newsroom culture. This essay presents an alternative interpretation and argues that bridging the gap between interaction design research, media and communications research, and practitioners within digital news media, could shed new light on the stalled process of newsroom co-creation with users.
\end{abstract}

\section{Keywords}

design; media; news; participation

Issue

This commentary is part of the issue "News and Participation through and beyond Proprietary Platforms in an Age of Social Media", edited by Oscar Westlund (Oslo Metropolitan University, Norway) and Mats Ekström (University of Gothenburg, Sweden).

(C) 2018 by the author; licensee Cogitatio (Lisbon, Portugal). This article is licensed under a Creative Commons Attribution 4.0 International License (CC BY).

\section{Participation and News Media: It's Complicated}

Since the Internet's childhood, the potential for participation has been present (Rafaeli, 1988). Early on, some scholars emphasized the need to develop "interactive journalism", favouring participation (e.g., Lawrence, 1993). At that time this was a challenging thought for the news industry, due to part of its identity being anchored in the gatekeeper role. Retrospectively, with 25 years of experimentation, news media have amassed substantial experience in the field. Conclusions differ regarding whether or not these attempts have been successful. We also note a trend of early adopters reducing or abandoning their efforts altogether.

As a manager and practitioner, I have followed the evolution of participatory journalism from an industry perspective. Since 2012, when I left my last operative post, I have been active on the board of the World Editors Forum and have served on Wan-Ifra award committees. From this outlook, I have gained somewhat of an international overview. Over the last five years, as the CEO of the Interactive Institute, an ICT and design research institute, I have experienced the strong impact that design-driven development can have on a multitude of application ar- eas. In this commentary, I argue that if interaction design was embedded in news media's innovation efforts and practices, participatory journalism could serve as a vehicle for a renaissance in journalism.

\section{Opening Up, Without Relinquishing Control}

In 2009, whilst working as Editor-in-Chief at the Swedish regional daily Norran, I developed an open news desk format, called the eEditor. The format rested on three pillars: transparency, dialogue, and feedback:

1) Transparency, being the daily publishing of the newsroom agenda and inviting the audience to influence the agenda, add know-how, suggest sources, and co-create content;

2) Dialogue, involving, discussion of topics and angles, new perspectives and follow-ups with the users;

3) Feedback, publishing the names of the participants who wished to be recognized.

Norran experimented with this format for three consecutive years, a work that fostered stronger ties to the lo- 
cal user base, increased both revenue and the paper's international reputation. (The Guardian, 2011; Wan-Ifra, 2011, 2012). Since then, parts of this strategy have been implemented by other news publishers, exploiting not only proprietary but non-proprietary platforms as well.

These different initiatives, however, have not been viewed as an overall success for the participatory formats. The reason for its so-called failure has often been attributed to an internal culture, unable to embrace change, and which is defensive of its institutionalized perception of what quality represents and what verification should entail (e.g., Ananny, 2018; Lewis, 2012). Behind the notion of reluctance, however, is the assumption of consciousness. This commentary introduces an alternative assumption: that it is the lack of awareness of the potential of interaction design that has hindered the development. Design thinking replaces the engineerled, linear, solution-focused innovation process with a user-centred process filled with loops leading step-bystep to a deeper cognitive understanding of the problem at hand. Using a combination of design thinking and an experimental approach, legacy media could develop ways of combining external contributions whilst maintaining high professional standards. This would shift the perspective from news media involving the users in the co-creation of their products to involving the media companies in the users' lives.

\subsection{Case Studies: Legacy Media Co-Creating with Users}

Early on, in 2008, CNN's iReport opened its platform to external contributions. The format has since evolved from a simple proprietary web page with a vague question ("What's happening?") to the use of a combination of proprietary and non-proprietary platforms as well as a stronger framing of the requested contributions, with assignments like "Show me how hot it is where you are?". Participation in open formats follows the 1-9-90 rule of thumb: $1 \%$ will actively contribute, $9 \%$ will actively contribute sometimes, and $90 \%$ will passively watch without contributing (Sloan, 2011). Experimentation with different designs to explore the elements which can have a positive impact on participation has been rare within news media.

One design feature that has been used is feedback loops. News publishers have tried different approaches, from paying contributors cash (e.g. Swedish Aftonbladet, 2018, who claims paying for "published tips and photo material") to personally inviting them into the editorial process (e.g., The Guardian's crowdsourcing initiatives; The Guardian, 2011-2013). Although design research results have indicated that the strongest engagement occurs when the matter relates to the user's personal experience of the service (Ghazarian, 2009). A more recent example is the Swiss, digital news magazine Republik which has managed to create co-ownership of the platform, using a similar methodology of open innovation and dialogue through conversation with users, as in the previously mentioned Norran example. As of April 2018, Republik had assembled 18,480 members and attracted CHF 4,595,000 in capital. Olivia Kühni, a journalist from Republik, says: "We believe people don't pay for articles anymore. They pay to be part of the community" (Niemanlab, 2018).

\subsection{Case Studies: Online Community Co-Creating Autonomously}

WikiTribune (2018), a follow-up initiative of Wikinews, aims to bring "journalists and a community of volunteers together" (Wales, 2017). WikiTribune has a simple, text-based design, filtering, and comments. Contributors are featured with names and pictures. Some contributors engage for these types of extrinsic rewards. Research on open source software communities has, however, indicated that collaborators participate for the intrinsic reward of contributing with their thoughts and ideas (Sharma, Sugumaran, \& Rajagopalan, 2002), a finding that should alter participatory innovation approaches in the journalistic context.

Over the past decade, pioneers in both the previously-mentioned categories have started limiting or abandoning their participatory efforts. Collaborative journalism site Newsvine, which operated from 2005, was closed by its owners in 2017. The community-driven Allvoices, which published user-generated news from 2008, closed in 2011 having reached 3 million unique visitors. In 2018, Huffington Post dissolved the part of its site which encouraged citizens to report on the news, attributing the decision to the upsurge in "misinformation online", relating to what Quandt (2018, this thematic issue) refers to as "dark participation". There is a need for further research to isolate general drivers and personal motivations behind this trend. Ultimately, is it time to give up on the vision of positive kinds of participatory journalism?

\section{Building a Bridge between Media and Design Research}

Scholars have argued that citizens have the right to a news narrative (Wall, 2017). In the post-mass-media era, legacy media are forced to transform, not only through new practices but also by shaping a new identity. It has been claimed that journalism's responsibility is "not only to influence masses by exposing them to ideas they might not seek for themselves but also to engage with them as people who can also produce novel and democratically valuable interpretations of social life" (Ananny, 2018). Having altered a legacy media company's brand proposition from "bringing you information" to "including you in building a successful future for our community", I believe this is a path which peers should explore.

We have seen how interaction design can point companies towards ways of building stronger relationships with their users. Traditional news media, whilst in a dif- 
ficult transition, could benefit from incorporating design intelligence into its business development. More tangible benefits range from broadened coverage, reduced information gathering costs, and stronger quality. It is important to remember that the early attempts at participatory journalism did not benefit from big data mining, artificial intelligence and block-chain technology, elements which should be included as this field moves forward. Some of the experiments took place in a time when the major industry currencies were quantitative: clicks and page views. Companies lacking a deeper understanding of the user relationship might have mistaken quantity with quality.

\section{Conclusions}

Participation is the default for a news outlet's current and future users. Younger generations are growing up connected, with AR-, VR-experiences, and sense-making games. The reason to continue developing interactive formats is that people love interaction, but it can also develop a sense of belonging and in doing so open individuals to the idea of cooperation. Consequently, news media would benefit strongly from integrating design thinking as well as new, participatory formats to strengthen customer relationships.

My experience indicates that not only is it possible to open the newsroom to external participation without relinquishing control, but also that transparent, interactive formats create a strong bond between the brand and the public. The process is complex, demanding digital as well as analogue interventions and cannot be simply copied into any context. By adopting interaction design research and practices, however, news media would have a guiding beacon and participatory journalism could fuel a journalistic renaissance within the networked world.

Finally, there is one more important rationale why attempts to find models for journalistic co-creation should not be abandoned: in a time when disinformation, security, and integrity issues are affecting users, as well as media distribution platforms' credibility, building coownership between quality news outlets and citizens should be more important than ever.

\section{Acknowledgements}

The author declares that this commentary was written in a personal capacity, rather than a professional capacity.

\section{Conflict of Interests}

The author declares no conflict of interests.

\section{References}

Aftonbladet. (2018). "Tipsa oss!". Retrieved from https://www.aftonbladet.se/tipsa
Ananny, M. (2018). Networked press freedom creating infrastructures for a public right to hear. Cambridge, MA: MIT Press.

Ghazarian, N. (2009). User studies within a living lab context (case studies from airport living lab). Uppsala: Department of Information Science, Uppsala University.

Lawrence, D., Jr. (1993). Why future is promising for newspaper industry. Newspaper Research Journal, 14(2), 11-17.

Lewis, S. (2012). The tension between professional control and open participation. Information, Communication \& Society, 15(6), 836-866.

Niemanlab. (2018). After crowdfunding success, Swiss magazine Republik charts a course to 'reclaim journalism as a profession'. Niemanlab. Retrieved from http://www.niemanlab.org/2018/05/after-crowdfund ing-success-swiss-magazine-republik-charts-a-course -to-reclaim-journalism-as-a-profession

Quandt, T. (2018). Dark participation. Media and Communication, 6(4), 36-48.

Rafaeli, S. (1988). Interactivity: From new media to communication. Sage Annual Review of Communication Research: Advancing communication science: Merging mass and interpersonal processes, 16, 110-134.

Sharma, S., Sugumaran, V., \& Rajagopalan, B. (2002). A framework for creating hybrid open-source software communities. Information Systems Journal, 12(1), 7-25.

Sloan, P. (2011). A guide to open innovation and crowdsourcing advice from leading experts in the field (1st ed.) London: Kogan Page.

The Guardian. (2011). The Guardian is opening up its newslists so you can help us make news. The Guardian. Retrieved from https://www.theguardian. com/media/2011/oct/09/the-guardian-newslistsopening-up

The Guardian. (2011-2013). Datablog + crowdsourcing. The Guardian. Retrieved from www.theguardian. $\mathrm{com} /$ news/datablog+technology/crowdsourcing

Wales, J. (2017). Wikipedia founder launches news website to combat the rise of 'alternative facts'. news.com.au. Retrieved from https://www.news. com.au/technology/online/wikipedia-launches-news -website-to-combat-the-rise-of-alternative-facts/news -story/905c6bf3d8e02d319ed7ee536e7038fo

Wall, M. (2017). Mapping citizen and participatory journalism. In newsrooms, classrooms and beyond. Journalism Practice, 11(2-3), 134-141.

Wan-Ifra. (2011). Social media and transparency at Swedish local paper Norran. In Trends in newsrooms 2011 (pp. 77-78). Frankfurt: Wan-Ifra.

Wan-Ifra. (2012). Building communities around your publication. In Trends in newsrooms 2012 (p. 81). Frankfurt: Wan-Ifra.

Wikitribune. (2018). About us. Wikitribune. Retrieved from https://www.wikitribune.com/about 


\section{About the Author}

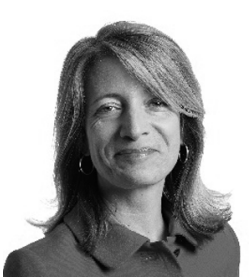

Anette Novak is the Director of the Swedish Media Council. She has had a long leadership career within media. As Editor-in-Chief of the regional daily Norran in Sweden she won international acclaim for launching a ground-breaking open newsdesk. She is the VP of the Fojo Media Institute and has previously held positions as Director of the board at the Swedish public service radio, the Swedish Media Publisher's Association, the Tinius Trust, and the World Editors Forum. Between 2013-2018, Novak was the CEO of the Interactive Institute and 2015 she was appointed to be the special counsel on future media policy by the Swedish government. 